Some new special issues of Elsevier Journals GEOCHEMICAL APPLICATIONS OF CRYSTAL FIELD THEORY

edited by W. F. Fyfe

Chemical Geology Vol. 5, No. 4.

f1.7.3 plus 2 s. postage (Dfl. 11.70 plus Dfl. 0.90 ).

SBN 444-40865-7

\title{
SUBMARINE CANYONS
}

edited by D. S. Gorsline

Marine Geology Vol. 8, No. 3/4.

£2.12.3 plus $2 s$. postage (Dfl. 21.60 plus Dfl. 0.90 ).

SBN 444-40863-0

\section{THE WORLD RIFT SYSTEM}

edited by L. Knopoff, B. C. Heezen and G. J. F. MacDonald

Tectonophysics Vol. 8, No. 4/5/6.

f3.17.6 plus $2 s$. postage (Dfl. 33.30 plus Dfl. 0.90 ).

SBN 444-40867-3

\section{EARTHQUAKE MECHANICS}

edited by T. Rikitake

Tectonophysics Vol. 9, No. 2/3.

f2.12.3 plus $2 s$. postage (Dfl. 22.50 plus Dfl. 0.90 ).

SBN 444-40864-9

MINERALOGISTS are invited to request a free specimen copy of the new journal THERMOCHIMICA ACTA which they may find of interest.

Orders and enquiries to your usual supplier or to Elsevier Publishing Company.

\section{Elsevier}

P.O. Box 211

AMSTERDAM - The Netherlands 